\title{
PERCEPÇÃO AMBIENTAL DE PRODUTORES RURAIS E CONDIÇÕES AMBIENTAIS DE ALGUMAS PROPRIEDADES AGRÍCOLAS DA REGIÃO DE BAURU-SP. ( DADOS PARCIAIS )
}

\section{Amauri Cassio Prudente Junior ${ }^{1}$}

Sérgio Luis de Carvalho ${ }^{2}$

Elizete Aparecida Checon Freitas Lima ${ }^{3}$

Resumo: Este trabalho tem como objetivo avaliar as condições ambientais de algumas propriedades rurais da região de Bauru - SP e de que maneira os problemas ambientais são percebidos pelos produtores rurais. Foi elaborado um questionário a partir do qual foram realizadas 30 entrevistas, com questões que detectaram a existência de degradação ambiental e a necessidade de um maior investimento na educação ambiental no meio rural da região de Bauru. Este questionário abordou temas referentes ao manejo e conservação do solo, uso de defensivos agrícolas, quais equipamentos de proteção são utilizados e se houve casos de contaminação, destino do lixo e do esgoto, tipos de

\footnotetext{
${ }^{1}$ Graduando em Agronomia, Unesp, Campus de Ilha Solteira.

${ }^{2}$ Prof. Adjunto, Doutor em Ecologia, Depto. de Biologia e Zootecnia da Unesp, Campus de llha Solteira. sergicar@bio.feis.br

3 Doutora em Ecologia, Depto. de Biologia e Zootecnia da Unesp, Campus de llha Solteira eacflima@bio.feis.br
} 
adubos e a importância da análise do solo, importância da mata ciliar e fontes de água e seu tratamento. O trabalho demonstra que tem que haver uma maior fiscalização nas propriedades, pois embora muitos proprietários demonstrem alguma percepção dos problemas ambientais, os conhecimentos não são aplicados em suas propriedades. Além disso são necessários investimentos em programas de educação ambiental pelos órgãos públicos sobre o quão importante é a preservação mostrando que todas as medidas estão diretamente ligadas a uma boa produção

Palavras-Chave: Educação Ambiental. Degradação Ambiental. Conscientização ambiental.

\section{INTRODUÇÃO}

Visando obter elevada produtividade, além da redução de custos com empregados, o produtor rural aumenta o emprego de máquinas agrícolas, da irrigação e de insumos para aumento da produção: fertilizantes, defensivos, corretivos de acidez do solo, engenharia genética, vacinações e energia elétrica, entre outros. Observa-se, entretanto, que cada um desses fatores de produção causa alguma degradação ambiental, resultando na compactação dos solos, na desertificação, na contaminação dos rios, na perda da biodiversidade genética, nas consequências ainda desconhecidas no enfraquecimento de espécies, na expansão descontrolada das fronteiras agrícolas, na destruição de formações vegetais nativas, queimadas na Amazônia e o corte predatório de árvores. (MOURA, 2004).

A perda pela natureza de sua capacidade de auto-regulação espontânea devido à magnitude e intensidade do impacto social sobre ela, tem atribuído ao homem a responsabilidade quase que total pela harmonização do intercâmbio entre a natureza e a sociedade. Mas é evidente que, para cumprir com êxito essa tarefa histórica - de cuja solução depende a vida do homem e, em conseqüência, a subsistência mesma da humanidade - o homem deve-se preparar, tanto do ponto de vista intelectual, quanto moral. Dai a necessidade e importância da educação ambiental das presentes e futuras 
gerações de cidadãos, da formação de recursos humanos nesta área e da elaboração das estratégias ecológicas correspondentes (SGUAREZI \& ARIAS, 1996)

A definição de educação ambiental, segundo o Congresso de Belgrado, promovido pela UNESCO em 1972 é de que ela é um processo que visa "formar uma população mundial consciente e preocupada com o ambiente e com os problemas que the dizem respeito, uma população que tenha os conhecimentos, as competências o estado de espírito, as motivações e o sentido de participação e engajamento que lhe permitam trabalhar individualmente e coletivamente para resolver os problemas atuais e impedir que se repitam". A educação ambiental é portanto, um processo permanente e participativo de explicitação de valores, instrução sobre problemas espeçíficos relacionados com 0 gerenciamento do meio ambiente, formação de conceitos e aquisição de competências que motivem o comportamento de defesa, preservação e melhoria do ambiente. Em outras palavras, a educação ambiental deve levar o homem a viver em harmonia com a natureza, passando pela participação de todos os cidadãos na solução dos problemas ambientais (SEARA FILHO, 1986).

A importância da pesquisa em percepção ambiental para o planejamento do ambiente foi ressaltada na proposição da UNESCO (1973), de que "uma das dificuldades para a proteção dos ecossistemas naturais está na existência de diferenças nas percepções dos valores e da importância dos mesmos entre os indivíduos de culturas diferentes ou de grupos sócio-econômicos que desempenham funções distintas, no plano social, nesses ambientes" (MAROTI \& SANTOS, 1998). Ampliando esta consideração foi também enfatizada a necessidade dos programas de conservação serem estabelecidos em função de imposições econômicas, sociais, culturais e ecológicas, bem como da percepção que as populações envolvidas têm do ambiente de estudo (BOUSQUET, 1988, citado por MAROTI \& SANTOS, 1998).

Desde o ano de 2000 está em desenvolvimento na UNESP, Campus de Ilha Solteira, um projeto de diagnóstico sócio-ambiental em propriedades agrícolas (pequenas, médias e grandes) no Estado de São Paulo, que busca coletar dados sobre as diversas realidades do meio rural do estado. Diversos trabalhos foram realizados no contexto de tal projeto, com a finalidade de avaliar as condições ambientais das propriedades rurais e a 
percepção ambiental de agricultores, entre os quais podem ser citados o de Arruda et al. (2001), no Assentamento Timboré em Castilho, SP, o de Poleto et al (2004), na Microbacia Hidrográfica do Córrego do Ipê em Ilha Solteira, SP, o de Martins (2005) no Assentamento Cinturão Verde de Ilha Solteira, o de Américo et al. (2012) em Dobrada, SP, e o de Carvalho et al. (2012), em Santa Rita do Passa Quatro, SP.

A metodologia utilizada baseia-se em MACHADO (1982), COLODRO et al. (1991) e MARTINS et al. (2005). Espera-se que os dados obtidos possam fornecer importantes subsídios para a elaboração de programas de educação ambiental, voltados para uma maior conscientização destes proprietários rurais.

\section{OBJETIVO GERAL}

O objetivo deste trabalho é avaliar as condições ambientais das propriedades rurais de Bauru e região e qual a percepção que os produtores tem acerca dos problemas ambientais. Outros trabalhos de percepção e condições ambientais foram realizados como o de Americo et.al em Dobrada-SP e Martins et al no Assentamento Cinturão Verde de Ilha Solteira.

\section{METODOLOGIA}

\subsection{Caracterização da Área de Estudo}

Bauru, com 359.429 habitantes (IBGE, 2009), tem como clima, o tropical de altitude, topografia com ondulações $64,71 \%$ e plano $23,85 \%$, agrega em seu território duas importantes vegetações, o cerrado e a mata atlântica (PREFEITURA MUNICIPAL, 2012). 
De acordo com a prefeitura municipal, o município de Bauru possui $673,49 \mathrm{Km}^{2}$ e está localizado a $345 \mathrm{Km}$ da capital de São Paulo, tem como longitude entre os meridianos 48 e 50 ao Oeste de Greenwich, e latitude entre os paralelos 21, 30 e 23 ao Sul do Equador, com altitude de $526 \mathrm{~m}$.

O clima da região é Aw, segundo a classificação de Köeppen (1948), apresentando uma temperatura média anual de $26,3^{\circ} \mathrm{C}$ (média das máximas de $32,2^{\circ} \mathrm{C}$ e das mínimas de $20,5^{\circ} \mathrm{C}$ ), com precipitação máxima em janeiro: $286 \mathrm{~mm}$ e mínima em julho: $33 \mathrm{~mm}$.

A principal atividade do município é o ramo de serviços com 66,4\% no PIB enquanto a indústria está com $31,7 \%$ e a agropecuário com 1,9\% ( PREFEITURA DE BAURU )

Na produção agrícola, tem como destaque a criação de gado bovino, que ocupa cerca de $90 \%$ da zona rural da cidade, de acordo com a secretária municipal de agricultura.

\subsection{Amostragens e Coleta de Dados}

Para coletar os dados foi formulado um questionário baseado em Machado (1982) e Martins et al. (2005), contendo 26 questões que dão uma abrangência sócio-econômicaambiental das propriedades rurais da região, tanto com perguntas abertas quanto as que permitem diferentes alternativas de respostas. As questões do questionário abordaram as questões ambientais mais críticas da atualidade, entre elas o destino final do lixo doméstico; contaminação por uso de agrotóxicos; descarte de embalagens de defensivos agrícolas; assoreamento e problemas de poluição nos cursos de água; problemas relacionados à conservação do solo e as técnicas de controle de erosão; preservação de matas nativas e ciliares e também, a percepção do produtor em relação à importância da conservação e disponibilidade dos recursos naturais para as gerações futuras. $O$ questionário foi aplicado em 30 propriedades rurais, incluindo pequenas médias e grandes, das cidades de Bauru, Fernão Dias, Arealva, Balbinos, Pirajuí, Reginópolis e distrito de Tibiriçá. As propriedades rurais foram escolhidas aleatoriamente e os dados coletados, permitem fazer uma análise sobre a necessidade de programas e melhorias na 
educação ambiental em âmbito regional. Também foram realizadas análises fotográficas, visando documentar e melhor avaliar as condições das propriedades rurais.

\section{RESULTADOS E DISCUSSÕES}

Com os dados obtidos do questionário, pode-se observar que na região de Bauru a principal atividade agrícola está na criação de animais, com destaque para a Pecuária que ocupa $86,67 \%$ da produção. A agricultura também tem significativa importância para os produtores, em que as principais culturas são a da cana de açúcar com $50 \%$ da produção e hortaliças com $26,67 \%$. O principal canal de comercialização ocorre por meio de intermediários em $66,66 \%$ das propriedades rurais. Em termos de assistência técnica, o órgão que mais assiste aos produtores é a Casa da Agricultura com 63,33\%.

Quanto ao tipo de adubo utilizado nas propriedades, $86,67 \%$ utilizam adubos químicos, 50\% utilizam adubação orgânica e 3,33\% utilizam adubação verde. Quanto ao calcário $86,67 \%$ das propriedades fazem uso desse produto, porém $70 \%$ dos produtores fazem análise do solo. Sendo assim uma parcela de 16,67\% estará sujeito a colocar quantidades indevidas afetando negativamente a fertilidade do solo.

Foi observado também a existência de problemas quanto a conservação do solo, em que $16,66 \%$ das propriedades apresentam erosão, voçoroca ou assoreamento. Desta porcentagem 10\% apresentam somente erosão, 3,33\% erosão e voçoroca e 3,33\% erosão e assoreamento. Em $100 \%$ das propriedades que apresentaram problemas, os produtores apontaram como causa a intensa chuva na região. Como medida de controle, $93,33 \%$ dos entrevistados utilizam o terraceamento, sendo que $80 \%$ praticam apenas essa técnica, enquanto $6,67 \%$ utilizam além das curvas de nível a manutenção da vegetação como maneira de controle, 3,33\% aderem a caixas de água e 3,33\% atribuem a colheita mecânica como fator favorável a conservação do solo. Do total, 6,67\% não utilizam nenhuma técnica para controlar possíveis problemas no solo. O ideal para se ter um solo bem manejado e livre de qualquer problemas de degradação é melhorar a infiltração investindo em rotação de culturas entre leguminosas e gramíneas, aumentar a quantidade de palhada e enfim fazer o terraceamento, porém todos estes métodos 
coligados não são aplicados em uma propriedade, sendo esta sujeita a adversidades tanto físicas quando químicas na estruturação do solo.

Quanto ao uso de defensivos agrícolas, 80\% das propriedades fazem uso destes produtos. Na hora da aplicação dos pesticidas, nota-se uma preocupação por boa parte dos produtores quanto a sua saúde (Figura 1). Mesmo assim houve casos de contaminação em $10 \%$ das propriedades rurais nos quais os principais sintomas citados foram depressão e fraqueza muscular em 33,3\% dos entrevistados, dor de cabeça e queda de pressão em 33,3\% e alterações nos exames de sangue em 33,3\%. O defensivo agrícola responsável em 66,66\% das propriedades onde ocorreram problemas à saúde do trabalhador foi um organofosforado e 33,33 \% não souberam informar.

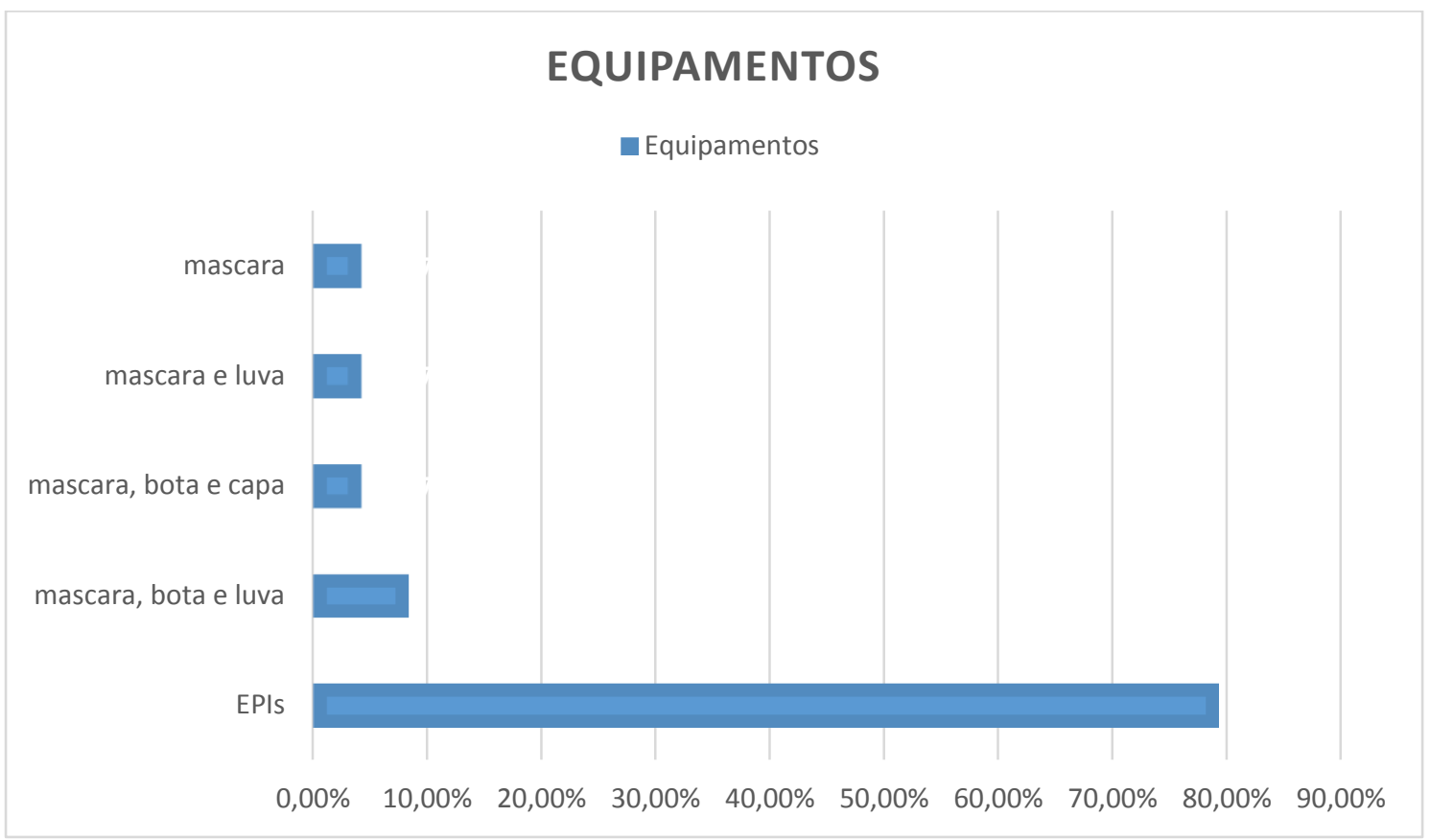

FIGURA 1: Equipamentos utilizados por produtores rurais da Região de Bauru-SP, 2013

A questão da existência e manutenção das matas ciliares também foi abordada. Em 76,67\% das propriedades rurais visitadas existe mata ciliar, sendo que $36,67 \%$ é cercada e preservada, 13,33\% é aberta e preservada, 10\% é aberta e em formação, $6,67 \%$ é aberta e de vegetação nativa original e $6,67 \%$ é cercada e em formação. Também foi perguntado sobre qual a importância das matas ciliares (Figura 2), em que 
observa-se em geral, boas ideias de preservação, porém foram notadas algumas carências de informações sobre os seus benefícios.

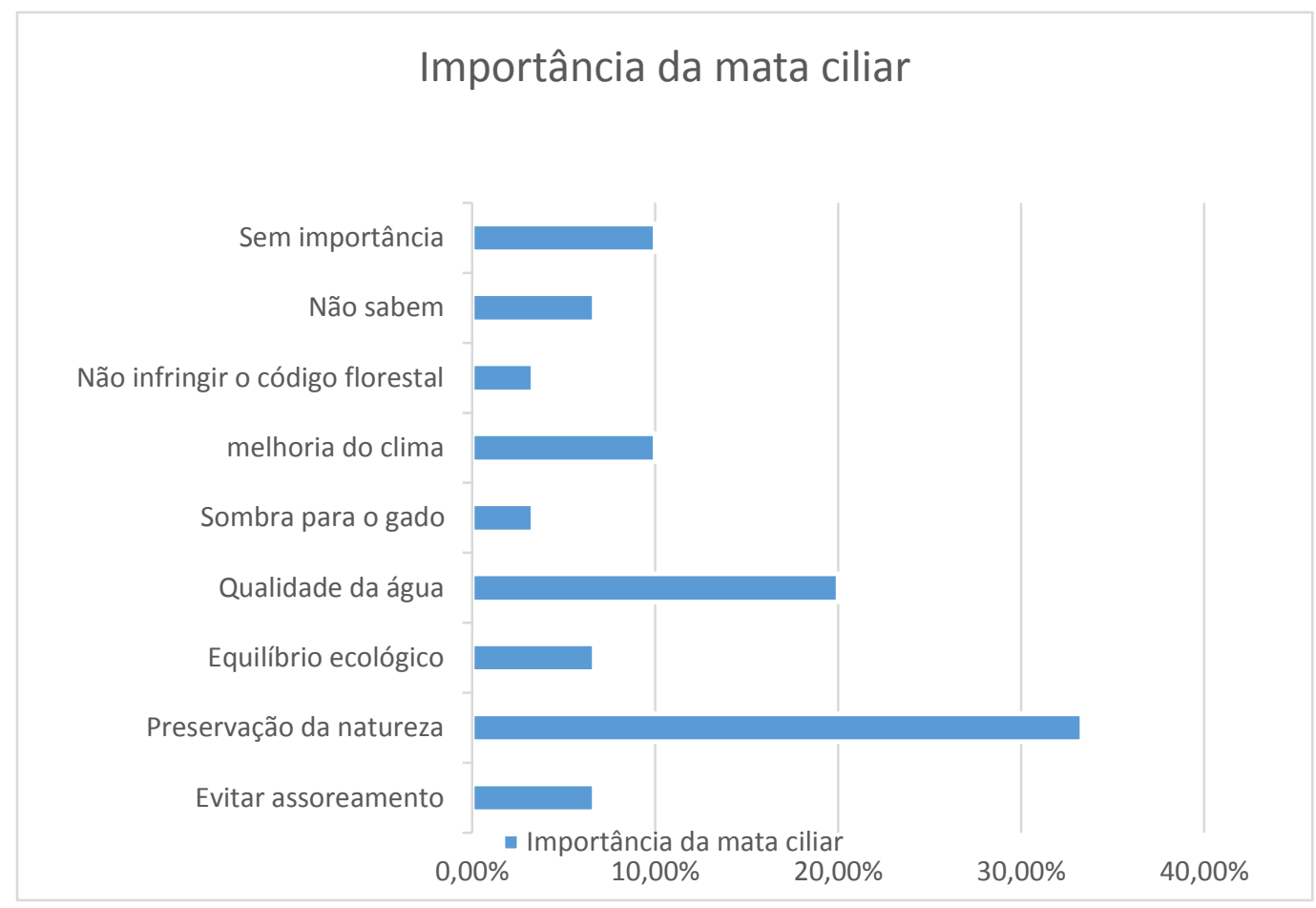

FIGURA 2: Importância da mata ciliar para os produtores rurais da região de Bauru-SP, 2013.

$\mathrm{Na}$ abordagem sobre as fontes de água presentes nas propriedades, $73,33 \%$ têm poços semi-artesianos, $36,67 \%$ apresentam nascentes, a mesma porcentagem também representa o rio como fonte de água, $26,67 \%$ das propriedades contém represas e este mesmo número evidencia a presença de córregos nos locais visitados, 13,33\% têm açudes e 3,33\% usam lagos como fonte de água. A água não é tratada em $93,33 \%$ das propriedades, podendo estar sujeita a impurezas que possam afetar aos produtores e aos animais que lá habitam. $O$ ideal seria fazer uma análise da água a fim de saber se ela está em condições de ser consumida, porém apenas 3,57\% dos proprietários preocupamse em faze-lo.

Um assunto que necessita total atenção, é sobre o destino do lixo, seja ele orgânico, papéis, latas, vidros ou plásticos. Algo positivo pode ser notado quanto ao local de descarte de resíduos, em que $20,67 \%$ é encaminhado para o lixão, $14 \%$ é reciclado e 
$8 \%$ coletado pelos catadores. Porém problemas também são detectados, pois 16,67\% dos produtores queimam o lixo, causando poluição do ar, com liberação de gases, os quais se exalados pelos mesmos, podem gerar problemas de saúde, além de prejudicar a estrutura do solo. Uma parcela de 2,67\% enterram os resíduos, 4\% despejam-nos em buracos, uma maneira errônea, pois, dependendo do tipo de lixo, pode ocorrer infiltração e contaminação do lençol freático e 4,67\% não apresentam lixo na propriedade. Nota-se que apesar de uma parcela apresentar destinos corretos ao lixo, ainda faltam informações sobre a maneira correta de descarte (Figura 3).

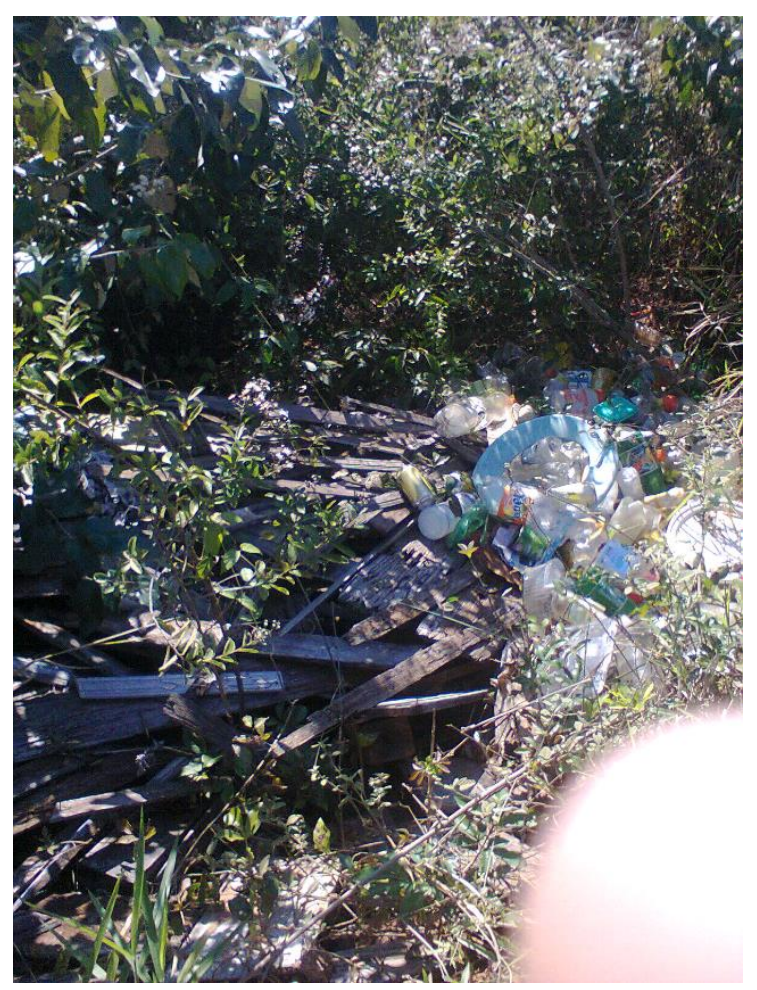

FIGURA 3: Exemplo de falta de informação por parte de produtores rurais que jogam lixos em aterros feitos na propriedade - Bauru, 2013.

O tipo de esgoto e onde este é despejado também foi questionado. Em $70 \%$ das propriedades existem fossas sépticas, em 16,67\% o esgoto é despejado em buracos, em $3,33 \%$ é despejado na mata ciliar (Figura 4), outros 3,33\% representam propriedades sem qualquer sistema de esgoto e por fim, 3,33\% despejam esgoto através de redes de 
tratamento da prefeitura local. Devido ao resultado, existe uma preocupação quanto ao contato dos dejetos com os lençóis freáticos, porém os relatos dos proprietários indicam que $86,67 \%$ não acreditam nesta possibilidade, mesmo sendo bastante provável que isso aconteça, tendo em vista que o ideal são redes de tratamento, evidenciando também a falta de auxilio da prefeitura quanto ao tratamento de esgoto nas propriedades.

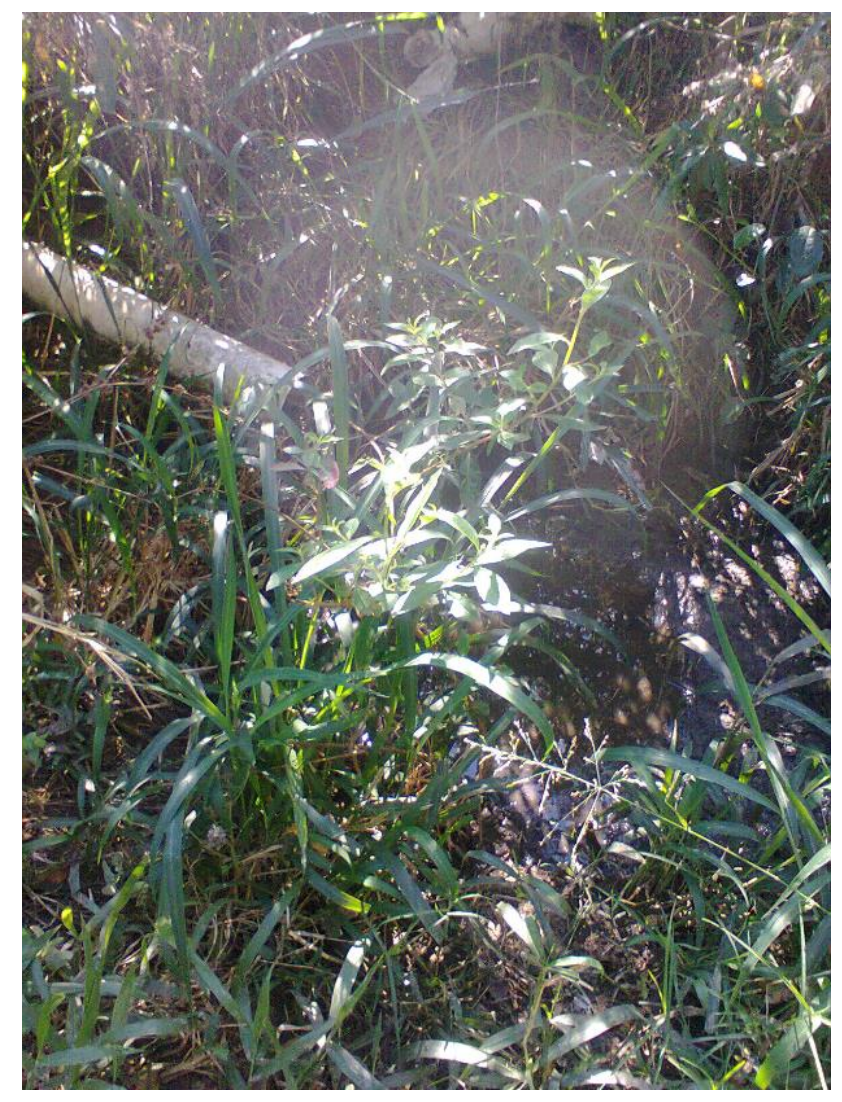

FIGURA 4: Esgoto sendo despejado na mata ciliar em uma das propriedades rurais da região de Bauru-SP, 2013.

\section{CONCLUSÃO}

O presente trabalho evidencia uma maior necessidade por parte dos órgãos públicos da região em investimentos na educação ambiental, tais como investir em 
palestras feitas pelas casas da agricultura, maior assistência a cooperativas que possam recolher embalagens, fomentar campanhas publicitárias sobre o quão importante é a preservação e mostrar que todas as medidas estão diretamente ligadas a uma boa produção. Tem que haver também uma maior fiscalização nas propriedades, pois embora muitos proprietários demonstrem alguma percepção dos problemas ambientais, os conhecimentos não são aplicados em suas propriedades.

\section{REFERÊNCIAS}

AMÉRICO, J.H.P.; CARVALHO, S.L.; FREITAS LIMA, E.A.C.;ARAÚJO, C.A.M. Condições ambientais de propriedades agrícolas e percepção ambiental de produtores rurais da região de Dobrada - São Paulo, Brasil. Holos Environment, v.12, n 2, p. 241-249, 2012.

AMORIM, D. A. Levantamento de Áreas Degradadas da Bacia do Alto do Rio Jacareí-Guaçu: propostas para recuperação. São Carlos, 1997. 121p. Dissertação de Mestrado - EESC/CRHEA, Universidade de São Paulo.

ARRUDA, S.A. CARVALHO, S.L.; FREITAS LIMA, E.A.C.;ARAÚJO, C.A.M. Percepção ambiental de produtores rurais e das condições ambientais de seus lotes agrícolas no Assentamento Timboré em Castilho-SP. In: III Encontro Sobre Educação Ambiental na Agricultura. Campinas-SP, 2001.

CARVALHO, S. L. ; ALMEIDA, F. ;FREITAS LIMA, E. A. C. Avaliação das Condições SócioEconômico-Ambientais de Algumas Propriedades Agrícolas no Município de Santa Rita do Passa Quatro SP. Fórum Ambiental da Alta Paulista, v. 8, p.348-359, 2012.

COLODRO, G., MORAES, M.L., CARVALHO, S.L. Conservação da natureza e Educação em Algumas Cidades do Estado de São Paulo. In: Seminário Regional de Ecologia, 6, 1989, São Carlos, Anais... UFSCAR,1991,529-546.

MACHADO, A.B.M. Conservação da Natureza e Educação. Silvicultura em São Paulo, v.16, n.1, p. 109-118, 1982.

MAROTI, P.S., SANTOS, J.E. Caracterização Perceptiva da Estação Ecológica de Jataí por Docentes do Ensino do Primeiro Grau. In: Seminário Regional de Ecologia, 8, 1998, São Carlos, Anais... UFSCAR, 1998, 475-485.

MARTINS, M. Avaliação das condições sócio-economico-ambientais de algumas propriedades agrícolas no município de Ilha Solteira. São Paulo. Monografia apresentada ao Curso de Agronomia da Faculdade de Engenharia-Campus de Ilha Solteira-São Paulo. 2005.

MOURA, L.A.A. Qualidade e Gestão Ambiental, 4.ed. São Paulo, Juarez de Oliveira, 2004, p.2745. 
MARTINS,M.;CARVALHO,S.L.; FREITAS LIMA,E.A.C.; ARAUJO,C.A.M.; SANTANA,A.L. Avaliação das condições sócio-econômicas de algumas propriedades agrícolas no município de Ilha Solteira/SP. In: Congresso Brasileiro de Administração Rural (ABAR), 5. 14-19 de agosto de 2005, Campinas. Anais...CD-ROM. 16p.

POLETO, C.; CARVALHO, S.L; FREITAS LIMA, E.C. Problemas de degradação ambiental em uma microbacia hidrográfica situada no município de Ilha Solteira - SP, Brasil e sua percepção pelos proprietários rurais. Holos Environment, v. 4, n.1, p. 68-80, 2004.

PREFEITURA MUNICIPAL BAURU. Disponível em: <http.www.bauru.sp.gov.br>. Acesso em 11 de setembro de 2013.

SGUAREZI , N. , ARIAS, J.O.C. Construindo Referências para a Formação de Recursos Humanos em Educação Ambiental . In: Seminário Regional de Ecologia, 8, 1998, São Carlos, Anais...UFSCAR, 1998, 427-437.

VERGARA FILHO, O., VALE, N., DUARTE, M., MACHADO, W.T.V., NUNES, A.E., SANTIAGO, A.N. A Educação Ambiental como Subsídio ao Projeto de ocupação das Encostas da Cidade do Rio de Janeiro. In: Seminário Regional de Ecologia, 8, 1998, São Carlos, Anais...UFSCAR, 1998, 449-458. 